\title{
Resurgence of behavior during extinction depends on previous rate of response
}

\author{
Phil Reed and Theresa A. Morgan \\ Swansea University, Swansea, Wales
}

\begin{abstract}
In two experiments, food-deprived rat subjects leverpressed for food in three successive training phases. In the first phase of both experiments, rats were exposed to a multiple schedule, one component of which produced a high rate of response, and the other of which produced a lower rate of response (multiple random ratio $[R R]$, random interval [RI] in Experiment 1, and multiple differential reinforcement of high rate, differential reinforcement of low rate in Experiment 2). Rats were then transferred to a multiple fixed interval (FI; 60-sec, $60-\mathrm{sec}$ ) schedule, until the effects of the first phase on response rate were no longer apparent and their response rates did not differ from those of rats responding on a multiple FI 60-sec, FI 60-sec schedule without previously experiencing a multiple RR, RI schedule. During the third stage of training, all rats were placed into extinction. During extinction, rates of responding were higher in the component previously associated with the high rate of responding in Phase 1, and they were lower in the component previously associated with low rates of responding in Phase 1. These results suggest that resurgence effects, like other history effects, are controlled by previous rates of responding.
\end{abstract}

There is a growing literature on the effects of an organism's behavioral history on its present performance. For example, two well-established examples of history effects include a "resistance to a change" in the operative contingencies (see, e.g., Nevin, 1974), and "renewal" effects (e.g., Lieving \& Lattal, 2003). Resistance to change has been extensively studied, and it has been shown that organisms previously trained on one contingency take longer to adapt to a second contingency than do organisms lacking this training. For example, prior exposure to a multiple variable interval (VI) 30 -sec, VI 120 -sec schedule, followed by exposure to a multiple extinction (ext), ext schedule, will retard extinction, and will result in more responding in the ext component than was previously associated with the VI 30-sec schedule (Nevin, 1974).

Resistance to change has been interpreted as a measure of response strength, and has been thought to reflect the relative rates of reinforcement experienced in the initial components of the multiple schedule used to build the behavioral history (Nevin, 1974, 1979; Nevin, Tota, Torquato, \& Shull, 1990). However, this interpretation has been challenged by a number of researchers, who have found that response rate, rather than reinforcement rate, is at least as important a predictor of resistance to change as is reinforcement rate (Doughty, Reed, \& Lattal, 2004; Lattal, 1989; Okouchi \& Lattal, 2006; Reed \& Doughty, 2005). For example, Lattal demonstrated that contingencies that produced different rates of response, but that delivered the same rates of reinforcement, were differentially disrupted; greater disruption was noted when response rates had been lower (see also Doughty et al., 2004). Con- versely, Okouchi and Lattal found that contingencies with different rates of reinforcement, but the same rates of response, were not differentially resistant to change.

Another procedure employed to investigate behavioral history effects has been used to examine the impact of prior training with variable ratio (VR) schedules on subsequent fixed interval (FI) performance. In a study reported by Wanchisen, Tatham, and Mooney (1989), rats responded for 30 sessions on a VR 20-sec schedule, prior to responding for 40 sessions on an FI 30-sec schedule. Relative to rats that responded only on the FI schedule, those in the former condition showed very little evidence of either scalloped response patterns (see Ferster \& Skinner, 1957) or the break-and-run pattern (Dews, 1978) typical of responding maintained by FI schedules. Instead, Wanchisen et al. (1989) reported that the rats tended to emit either high or low rates of responding on the FI schedule. This result evidences the potential impact of behavioral history on current performance (see also Reed \& Morgan, 2006; Tatham \& Wanchisen, 1998; Wanchisen, Sutphin, Balogh, \& Tatham, 1998, for similar history effects).

The fact that these history effects do not appear to last indefinitely in the face of exposure to a current schedule (see Baron \& Leinenweber, 1995; Cole, 2001; Freeman \& Lattal, 1992) is hardly surprising. Moreover, this relatively transient effect on overt performance does not mean that the behavioral history of the organism ceases to have the potential to impact current behavior. There are several instances where previously established patterns of behavior, apparently extinguished from the repertoire of the organism, reemerge into current performance. This class of his-

P. Reed, p.reed@swansea.ac.uk 
tory effects could be termed "renewal" effects, and comprises a number of different instances, each differentiated by the procedure used to generate them: induction, reinstatement, and resurgence (see Lieving \& Lattal, 2003, for a discussion). All three renewal effects initially reinforce a response in a first phase of training, and then extinguish the response in a second, subsequent, phase of training, so that its expression is removed from the manifest repertoire of the organism. The manner by which the expression of the response is renewed differentiates the three history effects. Induction techniques employ response-dependent reinforcement of another response in order to restore responding to the target (e.g., Reynolds, 1964), reinstatement effects are generated by the delivery of responseindependent reinforcement (e.g., Doughty et al., 2005; Doughty et al., 2004; Frank \& Lattal, 1976), and resurgence effects restore responding through the removal of contingencies that support an alternative response (e.g., Epstein \& Skinner, 1980; Leitenberg, Rawson, \& Mulick, 1975; Lieving \& Lattal, 2003; Mechner, Hyten, Field, \& Madden, 1997; Pear, 1985; Reed \& Morgan, 2006).

The present series of experiments concentrates on the latter phenomenon, resurgence, since it is one that has generated a great deal of discussion both theoretically (e.g., Shahan \& Chase, 2002) and clinically (e.g., Bouton, 2002). During a typical resurgence study, an organism is initially trained to emit one type of response. Following this, in a second phase of training, a second response is reinforced and the first response is extinguished. Finally, the second response is extinguished, and the first response reemerges into manifest behavior. The resurgence effect is one of particular generality, having being demonstrated to occur in experiments using a variety of types of response: for example, with identical responses (e.g., keypecks) emitted to a number of different keys (e.g., Leitenberg et al., 1975); topographically dissimilar responses, such as keypecks and treadle presses (Lieving \& Lattal, 2003); responses that are defined by extended temporal patterns of behavior (e.g., Pear, 1985); and responses constituting complex sequences of responding, such as patterns of responding across two levers (e.g., Reed \& Morgan, 2006). Several factors have been identified as important for the occurrence of resurgence. For example, a period of reduced reinforcement, although not necessarily extinction, for the second response is required in order for the first response to again become evident (Epstein, 1983; Lieving \& Lattal, 2003; Mulick, Leitenberg, \& Rawson, 1976). Additionally, the relative recency of the termination of reinforcement for the first response to the extinction of the second appears important in the degree to which resurgence occurs (Epstein \& Skinner, 1980; Lieving \& Lattal, 2003; Reynolds, 1964). Responses extinguished in a phase that is at a greater temporal distance from the resurgence-inducing phase tend to resurge more quickly into current behavior when reinforcement for the second response is reduced (it should be noted that there are some exceptions to this generalization; see Lieving \& Lattal, 2003, Experiment 1; Reed \& Morgan, 2006).

The present set of experiments aims to further document and extend knowledge about the factors that may influence the degree to which resurgence occurs, in order to address two questions. The main question tackled by the present series of experiments is whether resurgence is influenced by factors similar to those that produce other history effects (notably, rate of response during the history-building phases).

It has been shown that several history effects, such as resistance to change (Lattal, 1989; Okouchi \& Lattal, 2006; Reed \& Doughty, 2005), and reinstatement (Doughty et al., 2005; Doughty et al., 2004), appear in proportion to the rate at which the history response was emitted, rather than being a product of the history of rates of reinforcement. It is not currently known whether this also occurs in resurgence effects. Demonstration of control by similar factors across different history effects would help to expand knowledge of these history effects, and to provide a basis for the development of a common theory (see Lieving \& Lattal, 2003, for a discussion). Moreover, if previous rate of response was isolated as one factor responsible for the degree of resurgence, it might explain the sometimes seen primacy effect in resurgence studies (Mechner \& Jones, 2006; Reed \& Morgan, 2006). In these studies, when a series of responses has been sequentially trained, the last trained response resurges first (see also Leitenberg et al., 1975; Lieving \& Lattal, 2003; Reynolds, 1964); but with prolonged extinction, responses trained earlier in the initial sequence then resurge before those trained in the middle of the sequence. It may well be that the initially trained responses have a higher rate of emission than do the other responses in the series, perhaps due to relative lack of interference on the first response, and this allows them to resurge earlier than they otherwise might in extinction.

\section{EXPERIMENT 1}

The first experiment examined the impact on resurgence, during extinction of a novel behavior pattern, of initial training with schedules designed to produce either high or low response rates, despite having equal rates of reinforcement. Rats were initially trained on a multiple random ratio (RR), random interval (RI) schedule, which would lead to high response rates in the RR component and low response rates in the RI component (Peele, Casey, $\&$ Silberberg, 1984). A within-subjects yoking procedure was adopted to equate the rates of reinforcement in both components of the multiple schedule. This initial training was followed by exposure to a multiple FI 60 -sec, FI 60 -sec schedule. This schedule would produce equal rates in its two components, and different rates and patterns of responding than those controlled by the preceding multiple RR, RI schedule (see Cole, 2001; Freeman \& Lattal, 1992). Finally, once responding had become identical in the two components of the multiple FI, FI schedule, the rats were placed into a multiple ext, ext schedule. Their performance during extinction was monitored to see whether responding in the component previously associated with the RR schedule would be higher than that previously associated with the RI component, despite equal response rates in these components just prior to extinction. If the 
initial training schedule produced behavior that resurges in proportion to its rate of responding, then responding emitted during a final extinction phase should be greater in the component previously associated with the RR condition (i.e., that associated with a previously high rate of response) than would responding during extinction in the component previously associated with the RI condition (i.e., that associated with the lower rate of response).

\section{Method}

Subjects. Sixteen male experimentally naive hooded Lister rats served in the present experiment. The subjects were 3-4 months old at the start of training, had a free-feeding body weight range of $355-415 \mathrm{~g}$, and were maintained at $85 \%$ of this weight throughout the experiment. The animals were housed in groups of 4 , with water constantly available in the home cage.

Apparatus. Four identical operant conditioning chambers (Campden Instruments) were used. Each chamber measured $23.5 \times$ $23.5 \times 20.5 \mathrm{~cm}$ and was housed in a light- and sound-attenuating case, ventilated by a fan that provided background masking noise (65 dB[A]). Each chamber had two levers. Reinforcement consisted of 45-mg food pellets, delivered to a centrally located, recessed food tray that was covered by a clear Perspex hinged flap. The chamber was not illuminated during the experiment.

Procedure. All rats received magazine training in two 20-min random time 60 -sec sessions. Following this, the rats were taught to leverpress in two 20-min continuous reinforcement (CRF) sessions. During the first session, the left lever was inserted into the chamber, and during the second session the right lever was inserted into the chamber. Each of these sessions lasted for $20 \mathrm{~min}$. The rats were then moved to a multiple CRF, CRF schedule for two sessions. During these sessions, the light above one lever was illuminated for $5 \mathrm{~min}$. During this time, responses to that lever, but not to the other lever, were reinforced. There was then an intercomponent interval (ICI) of $30 \mathrm{sec}$, during which all lights were extinguished. Following the 30-sec ICI, the light above the other lever was illuminated for $5 \mathrm{~min}$, and the subjects were reinforced for responding to that lever, but not the other lever. This was repeated six times during the sessions (i.e., for a total of three 5-min exposures to each lever).

Phase 1 training. Following leverpress training, 8 rats were exposed to a multiple RR, RI schedule. Half the rats had the RR schedule on the right lever, and half had the RR schedule on the left lever. The components of the multiple RR, RI schedule were presented in strict alternation, as described above. The jeweled houselight located above the lever associated with the RR schedule was illuminated, and the house-light above the lever associated with the RI schedule was dark. This signaled the operation of the RR component, and responses to the other lever were ineffective. Following the 5-min exposure to the RR component, there was a 30-sec ICI, during which all houselights were extinguished. Then the houselight above the lever associated with the RI schedule was illuminated, and responses to this lever, but not to the other lever, were effective.

A within-subjects yoking procedure was adopted for this phase. For each rat, the mean interreinforcement interval (IRI) on the RR schedule during one component became the mean IRI for the RI schedule in the subsequent component.

The RR criterion value was increased over the course of this phase of training as follows: Sessions 1-2, RR5; Sessions 3-4, RR10; Sessions 5-6, RR15; Sessions 7-10, RR20; Sessions 11-15, RR25; Sessions 16-60, RR30. Each session comprised six 5-min exposures to the RR schedule component and six 5-min exposures to the RI schedule component. The other 8 rats received no training during this period.

Phase 2 training. Following Phase 1, all rats were exposed to a multiple FI 60 -sec, FI 60 -sec schedule. These sessions were conducted in a manner similar to that described above. There were six 5min exposures to each of the FI 60 -sec components, signaled by the illumination of the jeweled houselight located above the operative lever. There was no change in the stimuli used to signal the operation of the components from Phase 1 (i.e., the same jeweled houselight was employed). These component exposures were separated by a $30-$ $\mathrm{sec}$ ICI. Components were presented in strict alternation. This training continued for 36 sessions. During each session there were twelve 5-min components, six exposures to each FI 60-sec component.

Testing. Following Phase 2 training, all subjects were given two 20-min exposures to multiple ext, ext sessions. During these sessions, a light would be illuminated above one lever, and it remained illuminated for $5 \mathrm{~min}$. Responses to that lever were recorded but had no programmed contingencies. Then followed a 30 -sec ICI, when all lights were extinguished. After this, the light above the other lever was illuminated for $5 \mathrm{~min}$, and responses to this lever were recorded. This process was repeated once again for each lever. The order in which the extinction components were presented was counterbalanced so that the lever previously associated with the RR schedule was not always presented first. Half of the rats had the left lever presented first, and the remaining rats had the right lever presented first during the first test session; these rats had the other lever presented first for the second test session.

\section{Results and Discussion}

Figure 1 shows the group mean response rates emitted by the two groups to each component of the multiple schedules during both Phase 1 and Phase 2. Inspection of the data from Phase 1 shows that the component associated with the RR schedule came to support a higher rate of response than did the component associated with the RI schedule. A paired $t$ test was conducted on the last block of training, and a rejection criterion of $p<.05$ was adopted for this and all subsequent analyses. This $t$ test demonstrated a statistically significant difference between the components $[t(7)=6.52]$, with no statistically significant difference in the rate of response $(t<1)$. This result replicates the large number of within-subjects demonstrations of higher rates on an RR schedule than on an RI schedule, even with equal rates of reinforcement (e.g., Peele et al., 1984).

During Phase 2, the rates emitted by the RR, RI group to the two components of the multiple FI, FI schedule came to be highly similar to one another over the course of training. Rates in the FI component previously associated with the RR component remained higher than the rates on the FI component previously associated with the RI schedule for approximately 18 sessions of training (i.e., three 6-session blocks). Rates in the FI component previously associated with the RI component remained the same as their previous rate. Rates of response in the RR, RI group came to be similar to the rates in the FI, FI group over the course of training. By the end of Phase 2, response rates in each component for each group were highly similar. A two-factor ANOVA, with group as a between-subjects factor and component as a within-subjects factor, conducted on the last block of training revealed no main effects or interactions (all $F \mathrm{~s}<1$ ).

These data from Phases 1 and 2 show that prior exposure to a schedule has an effect on the next schedule to which the subjects are exposed, but that this effect dissipates relatively quickly. This temporary effect replicates previous work on the impact of history training with an RR schedule on subsequent FI performance (see Cole, 2001; Freeman \& Lattal, 1992), but provides no evidence for a relatively permanent impact of RR training on sub- 


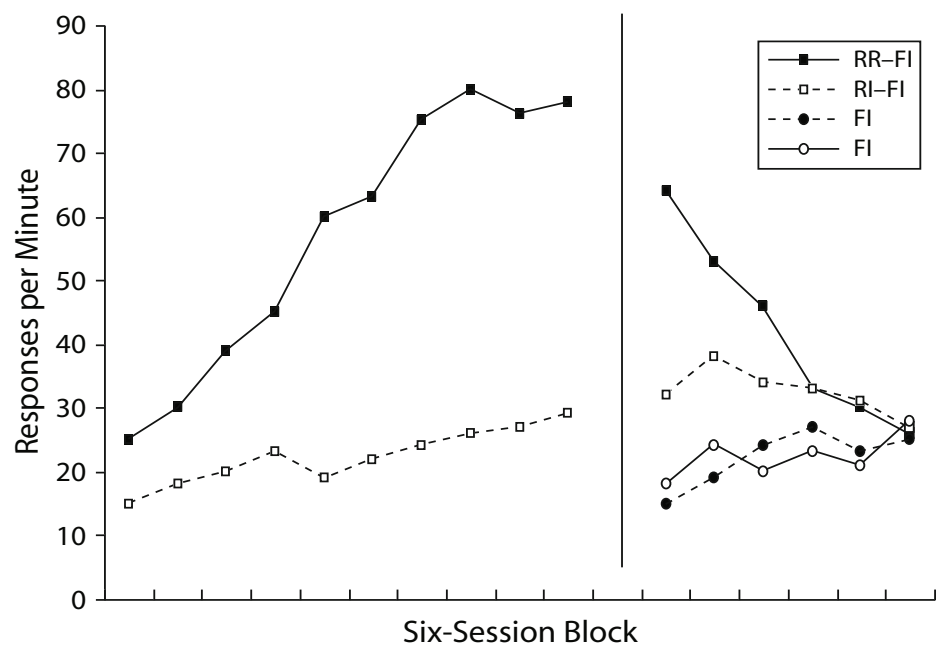

Figure 1. Results from Experiment 1. Left panel: Mean number of responses emitted in each six-session block of training during exposure to the multiple RR, RI schedule over the 10 six-session blocks of training in Phase 1. Right panel: Responses per minute emitted during the multiple FI, FI schedule in Phase 2. RR, random ratio; RI, random interval; FI, fixed interval.

sequent FI performance as suggested by Wanchisen et al. (1998; see also Weiner, 1964).

Figure 2 shows the group mean response rate over the two extinction sessions represented as 5-min blocks of extinction. It can be seen that rates of response in the two components of the multiple ext, ext schedule for the FI, FI group declined over the course of the test at a similar rate to one another. However, the pattern of results seen in the $\mathrm{RR}, \mathrm{RI}$ group was quite different. Rates of response in the extinction component previously associated with the RR schedule were initially higher than those in the extinction component previously associated with the RI schedule.

These data were analyzed in a three-factor ANOVA (group $\times$ component $\times$ block), which revealed significant main effects of group $[F(1,14)=61.01]$, component $[F(1,14)=26.32]$, and block $[F(3,42)=118.74]$. There were also statistically significant interactions of group $\times$ component $[F(1,14)=49.28]$, group $\times$ block $[F(3,42)=$ $3.99]$, and component $\times$ block $[F(3,42)=6.99]$.

The interactions were analyzed in separate two-factor ANOVAs (component $\times$ block) conducted for each group, as recommended by Howell (1997). The analysis for the FI, FI group revealed a significant main effect of block $[F(3,21)=121.02]$, but no main effect of component, nor any interaction of the two factors (both $p \mathrm{~s}>.10$ ). In contrast, the ANOVA conduced on the RR, RI group revealed a significant main effect of block $[F(3,21)=41.92]$, a significant main effect of component $[F(1,7)=43.31]$, and a significant interaction between the two factors $[F(3,21)=$ 5.58]. Comparison across the groups revealed that the component previously associated with the RR schedule had higher rates of response than did the component previously associated with the FI schedule on Test Blocks 2-5, inclusive [smallest $t(14)=3.24$ ]. However, the responding on the component previously associated with the FI was not different from that previously associated with the FI schedule (all $p$ s $>.40$ ).

The data from the test phase demonstrate that, although the effect of a previous schedule on current performance is not permanent in the organisms' overt performance, this does not mean that the effect does not have a potential impact on subsequent behavior. In fact, there was a latent effect on performance following training on the RR schedule, which was revealed during transfer to an extinction schedule. In this experiment, the components associated previously with high rates of response (i.e., the $\mathrm{RR}$ component) came to generate higher response rates in extinction relative to the rates for components previously either associated with low rates of response (i.e., the RI schedule) or not associated with a previous historybuilding schedule.

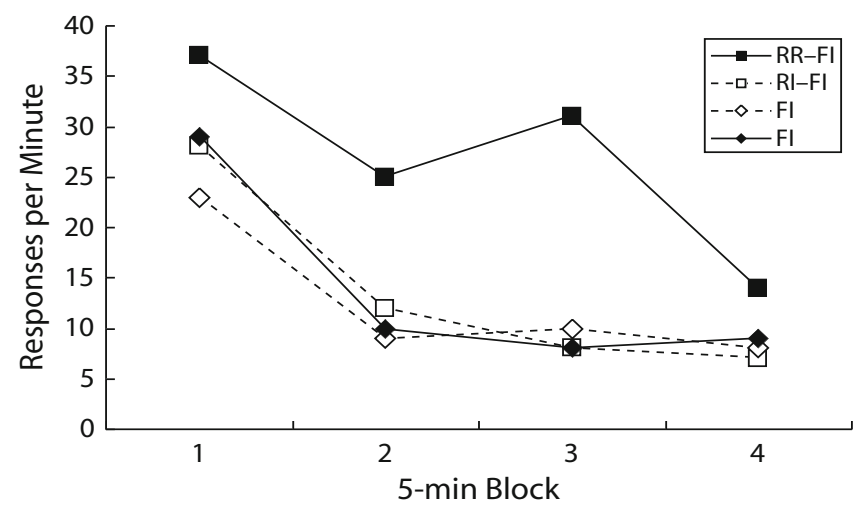

Figure 2. Results from Experiment 1. Mean number of responses emitted during each 5-min block of extinction. RR, random ratio; RI, random interval; FI, fixed interval. 
The greater resurgence effect noted in the component previously associated with the RR schedule relative to that previously associated with an RI schedule occurred despite the adoption of a yoking procedure in Phase 1 . This meant that the discriminative cues signaling the operation of the RR and RI schedules in Phase 1 could not have gained differential strength because of association with different rates of reinforcement during this phase. Thus, this potential explanation often offered as an explanation of reinstatement effects (Bouton, 1993; Nevin et al., 1990) cannot accommodate the present data. Rather, the importance of previous response rate in producing resurgence seems to be highlighted (see also Doughty et al., 2005; Doughty et al., 2004; Lattal, 1989, for similar findings).

\section{EXPERIMENT 2}

The results of Experiment 1 showed strong resurgence effects after exposure to an RR schedule that produced high rates of responding in a Phase prior to exposure to schedules that produced similar rates of responding. This finding suggests that resurgence is similar to both resistance to change (Lattal, 1989) and reinstatement (Doughty et al., 2004) in being controlled by this factor. In Experiment 2, we aimed to replicate these data by obtaining this effect in schedules devised to produce very high and low rates of response: a differential reinforcement of high rate (DRH) and a differential reinforcement of low rate (DRL) schedule.

Adopting this procedure also permits examination of a potential explanation of the results of Experiment 1. Experiment 1 ruled out the impact of differential reinforcement rates of the schedule used in the history-building phase as a potential source of the effect. However, it was not only rate of response that differed between the schedules as they progressed through the various transitions. In the transition from RR to FI schedules, there was a major change in the rate of responding emitted by the subjects, which was not so clearly the case for the transition from RI to FI schedules. Perhaps a history of changing contingencies (albeit unsignaled changes) associated with disrupted responding could have impacted the RR component in some unspecified way, so that any change in reinforcement contingencies would provoke disruption to the ongoing behavior more easily in this component. Hence, when transferred to the extinction schedule, the RR component showed greater disruption of performance than did the RI schedule. It is unclear what the mechanism of this disruption would be, but since response rate change was also a difference between the RR and RI components when transferred onto FI schedules, the use of DRH and DRL schedules as the "history" components would equate response rate change on transition to the FI schedule (both components would alter their rates), leaving only the initial response rates different.

\section{Method}

Subjects and Apparatus. Sixteen male experimentally naive hooded Lister rats served in the present experiment. The subjects were 3-4 months old at the start of training, had a free-feeding body weight range of 340-415 g, and were maintained as in Experiment 1. The apparatus was that described in Experiment 1.

Procedure. All rats were magazine and leverpress trained as in Experiment 1.

Phase 1 training. Following leverpress training, 8 rats were exposed to a multiple DRH, DRL schedule. Half the rats had the DRH schedule on the right lever, and half had the DRH schedule on the left lever. The components of the multiple DRH, DRL schedule were presented in strict alternation as in Experiment 1. The DRH criterion was made more severe over the course of training as follows: Sessions 1-3, DRH 3 responses in $10 \mathrm{sec}(3 / 10)$, DRL $5 \mathrm{sec}$; Sessions 4-6, DRH 3/8, DRL $7 \mathrm{sec}$; Sessions 7-9, DRH 3/6, DRL $9 \mathrm{sec}$; Sessions 10-15, DRH 3/5, DRL $10 \mathrm{sec}$; Sessions 16-20, DRH 4/5, DRL $10 \mathrm{sec}$; Sessions 21-25, DRH 4/4, DRL $10 \mathrm{sec}$; Sessions 26-60, DRH 5/3, DRL $10 \mathrm{sec}$. Each session comprised six 5-min exposures to the DRH schedule component and six 5-min exposures to the DRL schedule component. The other rats received no training during this period.

Phase 2 training. Following Phase 1, all rats were exposed to a multiple FI 60-sec, FI 60-sec schedule, as in Experiment 1. This training continued for 60 sessions.

Testing. Following Phase 2 training, all subjects were given two 20-min exposures to multiple ext, ext sessions. During these sessions, a light above one lever was illuminated for $5 \mathrm{~min}$. Responses to that lever were recorded but had no programmed contingencies. This was followed by a 30 -sec ICI, when all lights were extinguished. After this, the light above the other lever was illuminated for $5 \mathrm{~min}$, and responses to this lever were recorded but had no programmed consequences. This process was repeated once again for each lever. The order for the extinction components was counterbalanced across groups so that the lever previously associated with the DRH schedule was not always presented first.

\section{Results and Discussion}

Figure 3 shows the group mean response rates emitted by the two groups for each component of the multiple schedules during Phase 1 and Phase 2. Inspection of the data from Phase 1 shows that the component associated with the DRH schedule came to support much higher rates of responding than did the component associated with the DRL schedule. A paired $t$ test demonstrated a statistically significant difference between the components $[t(7)=$ 6.69] during the last six-session block of training.

During Phase 2, the rates emitted by the DRH, DRL group in the components of the multiple FI, FI schedules came together over the course of training. Rates in the FI component previously associated with the DRH component remained higher than the rates on the FI component previously associated with the DRL schedule for approximately 36 sessions of training (i.e., six to seven 6-session blocks). Rates in the FI component previously associated with the DRH component fell from their previous levels, and rates in the FI component previously associated with the DRL component increased from their previous levels. Rates of responding in the DRH, DRL group came to be similar to the rates in the FI, FI group over the course of training. By the end of Phase 2, response rates in each component for each group were highly similar. A twofactor ANOVA (group $\times$ component) conducted on the last block of training revealed no main effects or interactions (all $F_{\mathrm{S}}<1$ ).

As in Experiment 1, these data show that prior exposure to a schedule has an effect on the next schedule to which 


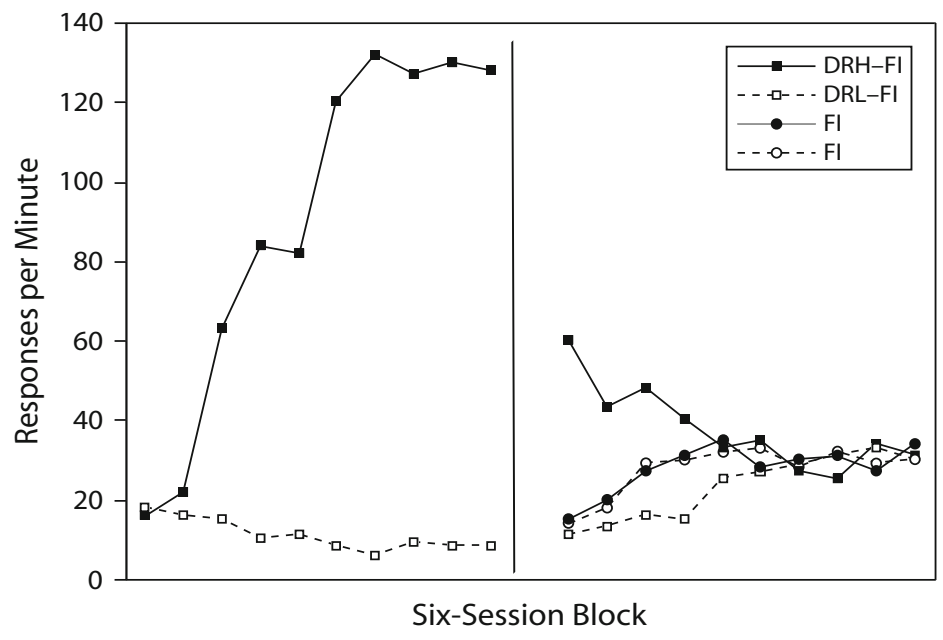

Figure 3. Results from Experiment 2. Left panel: Mean number of responses emitted in each six-session block of training during exposure to the multiple DRH, DRL schedule over the 10 six-session blocks of training in Phase 1. Right panel: Responses per minute emitted during the multiple FI, FI schedule in Phase 2. DRH, differential reinforcement of high rate; DRL, differential reinforcement of low rate; FI, fixed interval.

the subjects are exposed. In contrast to the results of Experiment 1, these effects were longer lasting than those found with an RR or an RI schedule. That is, response rates on the two FI 60-sec components in Experiment 2 took longer to converge after exposure to the DRH and DRL schedules than they did after exposure to the RR and RI schedules in Experiment 1 (36 sessions in Experiment 2, as opposed to 18 in Experiment 1). This was presumably due to the higher and lower response rates produced on the DRH and DRL schedules, respectively. Although this effect was longer lasting than that noted for RR and RI schedules, it still eventually dissipated by the end of training in Phase 2, suggesting the impermanence of previous history in overt behavior in the face of current contingencies (cf. Baron \& Leinenweber, 1995; Wanchisen et al., 1989).

Figure 4 shows the group mean rate of responding over the two extinction sessions represented as 5-min blocks of extinction. It can be seen that response rates in the two components of the FI, FI group declined to an equal extent over the course of extinction. However, the pattern of results seen in the DRH, DRL group was quite different. Response rates in the component previously associated with the DRH schedule were higher than those in the component previously associated with the DRL schedule. The rates in the previously conditioned DRH schedule were higher than those in the components in the FI, FI group, whereas the rates in the previously conditioned DRL component were slightly lower than the rates in the components of the FI, FI group.

These data were analyzed in a three-factor ANOVA (group $\times$ component $\times$ block), which revealed that all main effects, as well as two-way and three-way interactions, were statistically significant (smallest $F=6.02$ ). These interactions were analyzed further in separate two- factor ANOVAs (component $\times$ block) conducted for each group, as recommended by Howell (1997). The analysis for the FI, FI group revealed a significant main effect of block $[F(3,21)=52.20]$, but no main effect of component $(F<1)$, nor an interaction of the two factors $(p>.50)$. In contrast, the ANOVA conducted on the DRH, DRL group revealed a statistically significant main effect of block $[F(3,21)=30.79]$, a statistically significant main effect of component $[F(1,7)=66.78]$, and a statistically significant interaction between the two factors $[F(3,21)=$ 10.43].

Comparisons between the two groups over the course of extinction revealed that the component previously associated with the DRH schedule had higher rates of responding than did the component previously associated with the

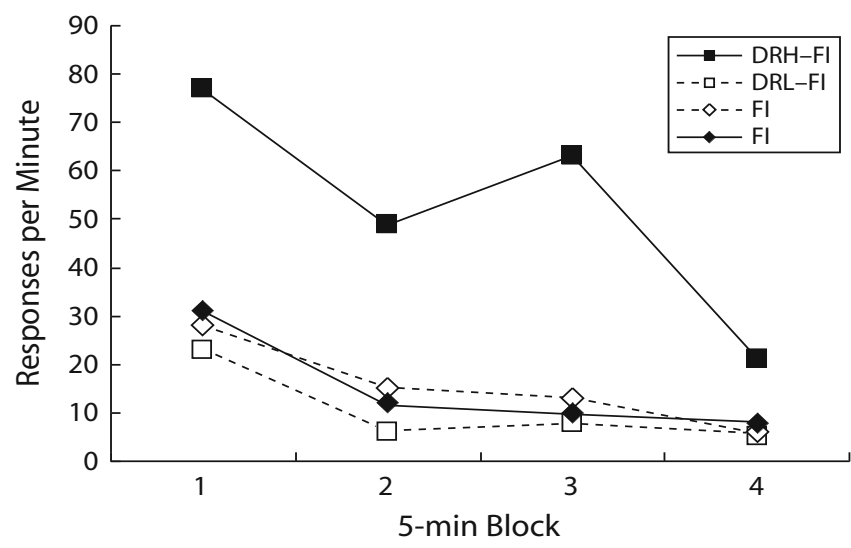

Figure 4. Results from Experiment 2. Mean number of responses emitted during each 5-min block of extinction. DRH, differential reinforcement of high rate; DRL, differential reinforcement of low rate; FI, fixed interval. 
FI schedule on all test blocks [smallest $t(14)=5.27]$. The component previously associated with the DRL schedule showed significantly lower rates of responding than did the component previously associated with the FI schedule on Block 2 of testing $[t(14)=2.64]$.

These results show that components associated with high rates of responding came to generate higher rates when in extinction than did the components previously associated with low rates of responding. The present procedure allowed a potential explanation of the effect noted in Experiment 1 to be examined: That is, when disruptions in rates of responding occur between phases, this may sensitize the subject to future changes in contingency and allow alterations in rate to emerge more readily. The results from the present experiment seem to rule out this explanation, because responding on the components associated with the DRH and the DRL schedules both altered after transition to the FI schedule (the DRH component reduced responding by a factor of five, and the DRL component increased responding by a factor of about three). Of course, because a stronger effect was generated by using schedules that produced much higher and lower rates of responding during the history component, and because this allowed for generalized sensitivity effects to be assessed, the rates of reinforcement experienced in the history-building phase were different. By the end of training on the DRH schedule, the mean rate of reinforcement was 9.6 reinforcements per minute, whereas on the DRL schedule, it was 4.2 reinforcements per minute. In themselves, these data could allow an explanation of the reversion effects on the basis of differential latent response strengths caused by the stimuli associated with the components of the multiple schedule having different associative strengths (Nevin et al., 1990). Of course, this does not negate the demonstration of the resurgence effect, but it provides an alternative explanation for it, albeit one that could not accommodate the data from Experiment 1.

\section{GENERAL DISCUSSION}

Two clear findings emerged from both of the present experiments. First, performance generated by exposure to a history-building schedule was eventually overridden by exposure to a different schedule. This supports claims about the importance of the present contingencies in determining performance (see Baron \& Leinenweber, 1995; Cole, 2001; Freeman \& Lattal, 1992). Second, when subjects were placed into extinction following exposure to the second contingency, the effects of the first history-training schedule showed resurgence (see Lieving \& Lattal, 2003; Pear, 1985; Reed \& Morgan, 2006). In particular, resurgence was more pronounced in components previously associated with a schedule producing high response rates (e.g., RR and DRH schedules) than it was in components previously associated with a schedule that produced low response rates (e.g., RI and DRL schedules).

The latter effect was the main focus of the present study, and it appears to support the claim made by Lieving and Lattal (2003) that there could be common mechanisms underlying the various forms of response renewal effects.
Previously it has been demonstrated that the strength of history effects such as resistance to change (e.g., Lattal, 1989; Okouchi \& Lattal, 2006; Reed \& Doughty, 2005) and reinstatement (e.g., Doughty et al., 2005; Doughty et al., 2004) is proportional to the rate of responding previously emitted on the history-building contingency, rather than being a primary function of the rate of reinforcement in the history-building contingency (see Bouton, 1993, 2002; Nevin, 1979; Nevin et al., 1990). This effect was demonstrable in the results of Experiment 1 during the resurgence extinction test (previously higher rates showed greater resurgence), and also in the comparison of the Phase 1 and Phase 2 transitions in both experiments (previously higher rates showed greater resistance to contingency alteration).

Theoretically, several explanations could accommodate the important controlling factors in generating renewal effects. Bouton (1993) suggested that, at least in Pavlovian conditioning, the associative strength of the cues used in the history-training phase might be critical in promoting reinstatement effects. This suggestion has also been made in operant settings, with respect to resistance to change procedures (see Nevin et al., 1990). However, the results from the present Experiment 1, where differential resurgence effects were noted despite equal rates of reinforcement in the history-building phase, coupled with the findings from other studies (e.g., Doughty \& Lattal, 2003; Doughty et al., 2004; Lattal, 1989; Lieving \& Lattal, 2003; Okouchi \& Lattal, 2006), suggest that this explanation cannot be complete. Both of the present experiments, as well as the previous work, suggest that the rate of responding, independently of other factors, determines the degree of resurgence observed during extinction. Thus, response rate appears to control resurgence as well as it controls reinstatement and resistance to change.

Response rate could act in many ways to produce such an effect, and it is unwise to speculate unduly, given that this was not the primary aim of the present study. However, one possibility is that the pattern of behavior generated by the history-building schedule comes to act as an integrated unit, and it is this previously learned unit that reemerges during extinction when a more recently learned response no longer brings reinforcement. Certainly, extended response patterns have been shown to act as behavioral units and are emitted whole according to other second-order schedules (e.g., Fetterman \& Stubbs, 1982; Reed, Schachtman, \& Hall, 1991; Schwartz, 1982); and such an explanation was briefly considered by Lieving and Lattal (2003) for their findings. The results of Experiment 2 are worth a brief note in this context. In the present study, there was evidence that if the rates of responding in the history-building phase were very low (as with a DRL schedule), placing the subject into extinction led to lower rates than those of subjects never exposed to such lowrate-producing schedules. The latter effect may be important, because it suggests that the pattern/rate of responding, not just responding per se, reemerges into behavior (see also Mechner et al., 1997; Wilson \& Hayes, 1996). It should be noted, however, that these low-rate resurgence (or perhaps better termed "reversion") effects, although 
statistically significant, were not as pronounced as the high-rate effects produced by either RR (Experiment 1) or DRH (Experiment 2) schedules. This was potentially due to differential floor and ceiling effects in extinction, or to the fact that the response rates maintained by the FI schedule were closer to those maintained by the DRL schedule than they were to those maintained by the DRH schedule. Future studies could use a smaller FI that maintains a higher rate of responding in order to investigate this issue further.

Leaving these speculations aside, the clear finding that response rate impacts the degree of resurgence may help to explain why recency effects dominate in most resurgence studies (e.g., Leitenberg et al., 1975; Lieving \& Lattal, 2003; see also Reynolds, 1964) yet primacy effects are sometimes noted (Mechner \& Jones, 2006; Reed \& Morgan, 2006). It may be that in studies that have yielded primacy effects in resurgence, the first-trained response may come to be emitted at a higher rate than that for the subsequently trained responses because there is no previous learning to interfere with the acquisition of a first response, whereas the learning of a first response may interfere with learning and/or expression of a second learned response. This would be expected especially in studies done with fixed phase lengths prior to a shift. Even when the second phase is conducted longer than the first, the first response has to be extinguished prior to acquisition of the second response, making higher rates of emission of the second response harder to obtain. If this is the case, coupled with the demonstration that resurgence is dependent on response rate, it may explain the conditions under which primacy occurs.

The fact that resurgence emerges during extinction or periods of reduced reinforcement also has similarities to other history findings, suggesting again that common factors may control several such history effects. It has been shown that history effects are stronger on transfer to schedules that control behavior only weakly in both resurgence (Lieving \& Lattal, 2003; Mechner et al., 1997) and resistance-to-change (Tatham \& Wanchisen, 1998) paradigms. It is also the case that when behavior is suppressed by punishment, previous behavior resurges (Dunham, 1971; Kelleher \& Morse, 1968). This suggests that prior training may have a strong tendency to recur under conditions that support current behavior only weakly. It would appear that these are the conditions often associated with the reemergence of depressive (Hooley \& Teasdale, 1989; Price, 1988) and psychotic (Reed et al., in press) episodes and are also the conditions under which helplessness emerges most strongly in humans (Reed, Frasquillo, Colkin, Leimann, \& Colbert, 2001). This suggests further and possible fertile lines of research to link basic and applied findings.

In addition to establishing behavioral reversion, the present research also illuminates the immediate effects of schedule transition. It has been claimed that previous exposure to a ratio schedule will produce a relatively permanent, or at least long-lasting, effect on subsequent FI schedule performance in rats, which is similar to that in humans (Wanchisen et al., 1989). That is, rats pretrained on ratio schedules have been shown to exhibit consistent high- or low-rate patterns on FI schedules, rather than the scalloped or break-and-run patterns that are typical of rats (Dews, 1978; Ferster \& Skinner, 1957). The former pattern has been noted extensively in human subjects (see Bentall, Lowe, \& Beasty, 1985), and Wanchisen et al. (1989) suggested that training history, rather than species differences, may be responsible for this different pattern of FI responding. Although this result was found by Wanchisen et al. (1989), it was found only over a short period of time by Cole (2001) and by Freeman and Lattal (1992), and not at all by Baron and Leinenweber (1995).

The present findings suggest that there is a temporary effect on response rate, but that it is not long lasting, corroborating the findings of Cole (2001) and Freeman and Lattal (1992). The length of this impact seems to depend on the rate of response (compare the effects of the DRH schedule in Experiment 2 with those of the VR schedule in Experiment 1), which perhaps is not surprising. Thus, these data cannot be taken as support for the view of Wanchisen et al. (1998; see also Weiner, 1964) regarding human FI performance being the product of training history.

In sum, the present results demonstrate that previously reinforced responses reemerged in the behavior of subjects during extinction (resurgence) to the extent that they had high rates of responding previously and not high rates of reinforcement. This effect has the potential to allow understanding of current performance as a product not only of the current contingencies, but also of prior training history, which can be latent in the repertoire of the organism. It also suggests common factors at play in the control of several history effects such as resurgence and reinstatement. Further exploration may allow a common theory to be developed for such effects, but whatever form such a theory takes, it must accommodate the effect of previous behavioral patterns and rates as well as the impact of previous reinforcement levels.

\section{AUTHOR NOTE}

This research was funded by a grant from The Mechner Foundation. Thanks are due the School of Psychology, University of Leeds, which made facilities available for the conduct of this work, and to Gillian Cardwell for her help with the care of the animals. Thanks are also due Lisa A. Osborne, Adam Doughty, and Andy Lattal for their support and comments on this research. Some of these data were presented at the First International Conference for the Association of Behavior Analysts, Venice, in 2001, and at the Third European Association for Behaviour Analysis Conference, Milan, in 2006. Correspondence concerning this article should be addressed to P. Reed, Department of Psychology, Swansea University, Singleton Park, Swansea SA2 8PP, Wales (e-mail: p.reed@swansea.ac.uk).

\section{REFERENCES}

Baron, A., \& Leinenweber, A. (1995). Effects of a variable-ratio conditioning history on sensitivity to fixed-interval contingencies in rats. Journal of the Experimental Analysis of Behavior, 63, $97-110$.

Bentall, R. P., Lowe, C. F., \& Beasty, A. (1985). The role of verbal behavior in human learning: II. Developmental differences. Journal of the Experimental Analysis of Behavior, 43, 165-181.

Bouton, M. E. (1993). Context and ambiguity in the extinction of emotional learning: Implications for exposure theory. Behaviour Research \& Therapy, 26, 137-149. 
Bouton, M. E. (2002). Context, ambiguity, and unlearning: Sources of relapse after behavioral extinction. Biological Psychiatry, 52, 976-986.

Cole, M. R. (2001). The long-term effect of high- and low-rate responding on fixed interval responding in rats. Journal of the Experimental Analysis of Behavior, 75, 43-54.

Dews, P. B. (1978). Studies on responding under fixed-interval schedules of reinforcement. New York: Appleton-Century-Crofts.

Doughty, A. H., Cirino, S., Mayfield, K. H., Da-Silva, S. P., OKouchi, H., \& LatTal, K. A. (2005). Effects of behavioral history on resistance to change. Psychological Record, 55, 315-330.

Doughty, A. H., \& Lattal, K. A. (2003). Response persistence under variable-time schedules following immediate and unsignalled delayed reinforcement. Quarterly Journal of Experimental Psychology, 56B, 267-277.

Doughty, A. H., Reed, P., \& Lattal, K. A. (2004). Differential reinstatement predicted by preextinction response rate. Psychonomic Bulletin \& Review, 11, 1118-1123.

Dunham, P. J. (1971). Punishment: Method and theory. Psychological Review, 78, 58-70.

EPSTEIN, R. (1983). Resurgence of previously reinforced behavior during extinction. Behaviour Analysis Letters, 3, 391-397.

EPSTEIN, R., \& SKINNER, B. F. (1980). Resurgence of responding after the cessation of response-independent reinforcement. Proceedings of the National Academy of Sciences, 77, 6251-6253.

Ferster, C. B., \& SkinNER, B. F. (1957). Schedules of reinforcement. New York: Appleton-Century-Crofts.

Fetterman, J. G., \& StubBs, D. A. (1982). Matching, maximizing, and the behavioral unit: Concurrent reinforcement of response sequences. Journal of the Experimental Analysis of Behavior, 37, 97-114.

Frank, G. J., \& Lattal, K. A. (1976). Antecedent reinforcement schedule training and operant response reinstatement in rats. Animal Learning \& Behavior, 4, 374-378.

Freeman, T. J., \& Lattal, K. A. (1992). Stimulus control of behavioural history. Journal of the Experimental Analysis of Behavior, 57, 5-15.

Hooley, J. M., \& Teasdale, J. D. (1989). Predictors of relapse in unipolar depressives: Expressed emotion, marital distress, and perceived criticism. Journal of Abnormal Psychology, 98, 229-235.

Howell, D. C. (1997). Statistical methods for psychology. New York: Duxbury Press.

Kelleher, R. T., \& Morse, W. H. (1968). Schedules using noxious stimuli: III. Responding maintained with response-produced electric shocks. Journal of the Experimental Analysis of Behavior, 11, 819-838.

LatTAL, K. A. (1989). Contingencies on response rate and resistance to change. Learning \& Motivation, 20, 191-203.

Leitenberg, H., Rawson, R. A., \& Mulick, J. A. (1975). Extinction and reinforcement of alternative behavior. Journal of Comparative \& Physiological Psychology, 88, 640-652.

Lieving, G. A., \& LatTal, K. A. (2003). Recency, repeatability, and reinforcer retrenchment: An experimental analysis of resurgence. Journal of the Experimental Analysis of Behavior, 80, 217-233.

Mechner, F., Hyten, C., Field, D. P., \& Madden, G. J. (1997). Using revealed operants to study the structure and properties of human operant behavior. Psychological Record, 47, 45-68

Mechner, F., \& Jones, L. (2006). Number of prior repetitions of operants, and resurgence. Retrieved June 24th, 2006, from mechnerfoundation.org/pdf_downloads/number_of_repetitions.pdf.

Mulick, J. A., Leitenberg, H., \& Rawson, R. A. (1976). Alternative response training, differential reinforcement of other behavior, and extinction in squirrel monkeys (Saimiri sciureus). Journal of the Experimental Analysis of Behavior, 25, 311-320.

Nevin, J. A. (1974). Response strength in multiple schedules. Journal of the Experimental Analysis of Behavior, 21, 389-408.
Nevin, J. A. (1979). Reinforcement schedules and response strength. In M. D. Zeiler \& P. Harzem (Eds.), Reinforcement and the organisation of behaviour (pp. 117-158). Chichester, U.K.: Wiley.

Nevin, J. A., Tota, M. E., Torquato, R. D., \& Shull, R. L. (1990). Alternative reinforcement increases resistance to change: Pavlovian or operant contingencies? Journal of the Experimental Analysis of Behavior, 53, 359-379.

OкоUChi, H., \& Lattal, K. А. (2006). An analysis of reinforcement history effects. Journal of the Experimental Analysis of Behavior, 86, $31-42$

Pear, J. J. (1985). Spatiotemporal patterns of behavior produced by variable-interval schedules of reinforcement. Journal of the Experimental Analysis of Behavior, 44, 217-231.

Peele, D. B., Casey, J., \& Silberberg, A. (1984). Primacy of interresponse-time reinforcement in accounting for rate differences under variable-ratio and variable-interval schedules. Journal of Experimental Psychology: Animal Behavior Processes, 10, 149-167.

PRICE, J. S. (1988). Alternative channels for negotiating asymmetry in social relationships. In M. R. A. Chance (Ed.), Social fabrics of the mind (pp. 157-196). Hove, U.K.: Erlbaum.

Reed, P., \& Doughty, A. H. (2005). Within-subject testing of the signaled reinforcement effect on operant responding as measured by response rate and resistance to change. Journal of the Experimental Analysis of Behavior, 83, 31-45.

Reed, P., Frasouillo, R., Colkin, C., Leimann, V., \& Colbert, S. (2001). Interference with judgments of control and learning as a result of prior exposure to controllable and uncontrollable feedback during concept learning tasks. Quarterly Journal of Experimental Psychology, 54B, 167-183.

Reed, P., \& Morgan, T. A. (2006). Resurgence of response sequences during extinction in rats shows a primacy effect. Journal of the Experimental Analysis of Behavior, 86, 307-315.

Reed, P., Schachtman, T. R., \& Hall, G. (1991). Effect of signaled reinforcement on the formation of behavioral units. Journal of Experimental Psychology: Animal Behavior Processes, 17, 475-485.

Reed, P., Wakefield, D., Harris, J., Parry, J., Cella, M., \& TsakanIKOS, E. (in press). Seeing non-existent events: Effects of environmental conditions, schizotypal symptoms, and sub-clinical characteristics. Journal of Behavior Therapy \& Experimental Psychiatry.

REYNOLDS, G. S. (1964). Operant extinction near zero. Journal of the Experimental Analysis of Behavior, 7, 173-176.

SCHWARTZ, B. (1982). Interval and ratio reinforcement of a complex sequential operant in pigeons. Journal of the Experimental Analysis of Behavior, 37, 349-357.

Shahan, T. A., \& Chase, P. N. (2002). Novelty, stimulus control, and operant variability. Behavior Analyst, 25, 175-190.

Tatham, T. A., \& Wanchisen, B. A. (1998). Behavioral history: A definition and some common findings from two areas of research. Behavior Analyst, 21, 241-251

Wanchisen, B. A., Sutphin, G. E., Balogh, S. A., \& Tatham, T. A. (1998). Lasting effects of a behavioral history of low-rate responding in rats. Learning \& Motivation, 29, 220-235.

Wanchisen, B. A., Tatham, T. A., \& Mooney, S. E. (1989). Variableratio conditioning history produces high- and low-rate fixedinterval performance in rats. Journal of the Experimental Analysis of Behavior, 52, 167-179.

WeINER, H. (1964). Conditioning history and human fixed-interval performance. Journal of the Experimental Analysis of Behavior, 7, 383-385.

Wilson, K. G., \& HaYes, S. C. (1996). Resurgence of derived stimulus relations. Journal of the Experimental Analysis of Behavior, 66, 267-281.

(Manuscript received November 18, 2006; revision accepted for publication April 6, 2007.) 